\title{
Unemployment and Market Size
}

\author{
Martin Ellison, ${ }^{*}$ Godfrey Keller, Kevin Roberts and Margaret Stevens ${ }^{\dagger}$ \\ Department of Economics, University of Oxford
}

February 14, 2013

\begin{abstract}
Without strong empirical support, random matching models of the labour market typically assume constant returns to scale in matching. We construct a tractable equilibrium random matching model with a general matching technology, introducing market size effects: the job-finding rate varies with the level of unemployment. Stable steady-state equilibria may occur in regions of increasing or decreasing returns in matching; when multiple equilibria arise they are welfare-ranked by market size. We show that, while the standard model relies on high-frequency shocks to the steady state to explain the observed joint variation of unemployment and the job-finding rate, locally decreasing returns in matching generate plausible adjustment dynamics and slower convergence. Lastly, an extension of the Hosios condition internalises search externalities.
\end{abstract}

JEL Classification Numbers: J41, J64

Keywords: Unemployment, Job Search, Matching Function, Returns to Scale, Multiple Equilibria, Stability, Dynamics, Search Efficiency.

\section{Introduction}

Random matching models capture the implications of labour market frictions by specifying a matching function: the rate at which workers and firms meet is a function of the numbers of agents on each side of the market. A natural property of the matching function is that the rate at which an individual agent matches depends on market tightness the relative number of agents on each side of the market. It may also depend on the absolute number of agents: a market could be too small to support effective mechanisms for

\footnotetext{
* Department of Economics and Bank of Finland

${ }^{\dagger}$ Corresponding author
} 
exchanging information about opportunities for trade, or so large that participants suffer from information overload. Market size effects were the focus of Diamond's (1982) model of multiple equilibria and co-ordination failure, but have since received little attention in the extensive matching literature. The dominant equilibrium random matching model of the labour market, most fully described by Pissarides (2000), rules them out by assuming a matching function with everywhere-constant returns to scale, usually justified by an appeal to empirical evidence together with a desire for tractability.

But the evidence for constant returns is not compelling. Of the eight aggregate studies surveyed by Petrongolo and Pissarides (2001), only three - Pissarides (1986) and Layard, Nickell and Jackman (1991) for Britain, and van Ours (1991) for the Netherlands - support constant returns. Two studies (Burda and Wyplosz, 1995, for France, Germany, Spain and the UK; Berman, 1997, for Israel) obtain decreasing returns, and three (Blanchard and Diamond, 1990, and Warren, 1996, for the US; Yashiv, 2000, for Israel) find increasing returns. The evidence for disaggregated markets is similarly mixed: substantial departures from constant returns have been found for regional and occupational markets. ${ }^{1}$

The constant returns assumption means that the dynamic behaviour of the Pissarides model is very simple: away from the steady state unemployment evolves slowly, but when unemployment rises hiring rises too - the scale of the market changes in proportion to the level of unemployment. Market tightness and the job-finding rate remain constant at their equilibrium values; workers are thus indifferent to the rate of unemployment, so the reservation wage does not change either. To reconcile the basic model with the observed dynamic variation in job-finding rates (Shimer, 2005) it is therefore necessary to assume high-frequency shocks to productivity or other parameters. Hall (2005) argues explicitly that turnover dynamics are irrelevant, showing that unemployment closely tracks its steady-state level. But as we will show in this paper, his argument relies on constant returns; an alternative explanation is provided by dynamic adjustment under decreasing returns.

We present an equilibrium matching model of the labour market with a general form for the matching function, to take account of market size effects. We show that this generalisation is quite tractable: steady-state equilibria with non-constant returns have simple properties, and we can fully describe the dynamic behaviour of labour market variables.

\footnotetext{
${ }^{1}$ For travel-to-work areas in Britain, the results of Coles and Smith (1996) support constant returns, but Burgess and Profit (2001) allow for area fixed effects and find decreasing returns. Kano and Ohta (2005) also obtain decreasing returns for Japanese regions. Several studies of local labour markets have found increasing returns: Kangasharju, Pehkonen and Pekkala (2005) for Finland; Baker, Hogan and Ragan (1996) for Canada; and Munich, Svejnar and Terrell (1999) for the Czech Republic. Fahr and Sunde (2004) find increasing returns for craft and technical occupations, and substantially decreasing returns for white collar occupations and for highly educated workers.
} 
In this richer dynamic environment, the job-finding rate, and hence the incentives for job creation and reservation wages, vary with the level of unemployment.

After specifying the model in section 2, we obtain conditions for existence and local stability of steady-state equilibria in section 3. Multiple equilibria are welfare-ranked according to market size, irrespective of the shape of the matching function. Dynamics are analysed in section 4: provided that returns to scale do not increase steeply, steadystate equilibria are saddle-path stable. Following a shock that increases unemployment, reservation wages either rise or fall depending on the direction of the market size effect, and reservation wages and market tightness adjust along the saddle path. The rate of convergence also depends on returns to scale. We provide simulations to demonstrate the quantitative implications of decreasing returns: the effect of shocks on unemployment is amplified, and there is a modest increase in persistence; in addition, decreasing returns contribute substantial variation in the job-finding rate, while the wage remains relatively insensitive to unemployment.

The extension to non-constant returns is completed in section 5, where we compare decentralised equilibria with the efficient allocation, and derive a generalisation of the wellknown Hosios condition for efficiency. As for the constant returns case, the decentralised equilibrium can be efficient if the shares of the surplus obtained by workers and firms are equal to the elasticities of the matching function with respect to unemployment and vacancies. Thus efficiency requires an employment tax with decreasing returns, or a subsidy with increasing returns.

\section{Related Literature}

\subsection{Labour Market Matching Models with Constant Returns}

Equilibrium random matching models are now well-established as a framework for understanding unemployment (Pissarides, 2000). This search-theoretic approach is consistent at a microeconomic level with many features of observed labour market behaviour (Rogerson, Shimer and Wright, 2005). At the aggregate level, the model provides a theory of equilibrium unemployment, predicting labour market flows broadly consistent with business cycle evidence (Mortensen and Pissarides, 1994 and 1999; Cole and Rogerson, 1999). Incorporating labour market matching improves the ability of RBC models to reproduce macroeconomic stylised facts (Merz 1995, 1999; Andolfatto, 1996; and Den Haan, Ramey and Watson, 2000).

However, Shimer (2005) has shown that the Mortensen-Pissarides model cannot ac- 
count for the strong procyclicality of the job-finding rate and market tightness (the $v-u$ ratio). Rogerson and Shimer (2011) argue that introducing search frictions into an RBC model with indivisible labour does not directly improve its ability to account for the amplification and persistence of shocks in their effects on the labour market. One response has been to challenge the wage-bargaining assumption and argue that wages are sticky (e.g. Hall and Milgrom, 2008). Others have focused on the role of capital adjustment: Den Haan, Ramey and Watson (2000) showed that interactions between capital adjustment and job destruction could enhance the propagation of shocks, particularly in the presence of adjustment costs. In an alternative approach, Hagedorn and Manovskii (2008) argue that the model should be seen as an approximation to a more general model in which the production technology and non-market utility are non-linear, which changes calibrated parameter values. $^{2}$

The efficiency properties of matching models with constant returns are well-understood. With homogeneous agents, Hosios (1990) showed that externalities are internalised if the bargaining share of workers is equal to the elasticity of matching with respect to unemployment. In this environment, all external effects act through market tightness, and a single condition for relative surplus shares is sufficient to ensure that agents make efficient search and matching decisions.

\subsection{Non-Constant Returns, Multiple Equilibria and Dynamics}

In the elegant stylised model of Diamond (1982) there is only one type of searching agent. Trading opportunities occur when agents meet each other, and their meeting rate increases with the number of searchers, generating multiple equilibria. Diamond and Fudenberg (1989) analyse the dynamics of the Diamond model, and Boldrin, Kiyotaki and Wright (1993) provide an analysis of dynamics in a generalisation of the model with differentiated commodities, focusing on the existence of limit cycles.

The assumption of a single type of agent limits the applicability of the Diamond model, although Camera (2000) uses this approach to obtain multiple equilibria in a monetary search model. There are few analyses of the implications of non-constant returns to scale when the matching function depends separately on the numbers of buyers and sellers. Pissarides (1984) shows that with a general matching technology equilibria are inefficient - the Hosios (1990) condition requires constant returns - and Howitt and McAfee (1987) use a specific increasing returns technology to introduce Diamond's thin-market exter-

\footnotetext{
${ }^{2}$ Other critiques and generalisations of the standard model have focused on the need to allow for the participation margin (Cole and Rogerson, 1999; Veracierto, 2004; Garibaldi and Wasmer, 2005; Alvarez and Shimer, 2011).
} 
nality into a labour market model, again emphasising inefficiency. Burdett and Wright (1998) model a labour market with fixed and equal numbers of agents on both sides, and idiosyncratic match productivity; multiple equilibria may occur either as a result of increasing returns in matching or non-transferable utility, but are ruled out when the productivity distribution is log-concave. ${ }^{3}$

None of the analyses of labour market models with non-constant returns to scale in matching considers dynamics, although Mortensen (1989) suggests that they will be similar to those of matching models with aggregate increasing returns in production (Drazen, 1988; Mortensen, 1999). This paper shows that escaping the straitjacket of constant returns permits a richer dynamic structure to emerge: importantly, it generates plausible out-of-steady-state dynamics which (in contrast to the constant-returns case) can contribute to explaining the temporal behaviour of labour market variables.

\section{The Model}

\subsection{The Matching Technology}

Unemployed workers and potential employers meet randomly according to a matching technology that determines the meeting rate, $M$, as a function of the mass of unemployed workers, $u$, and the mass of vacant jobs, $v$ : $M=M(u, v)$. We assume that $M(0, v)=M(u, 0)=0$, and that $M$ is strictly increasing in both arguments, homothetic, and quasi-concave. ${ }^{4}$ Hence it can be expressed:

$$
M=\Phi(m(u, v))
$$

where $\Phi$ is a strictly increasing function, $\Phi(0)=0$, and $m(u, v)$ is homogeneous of degree one with strictly convex isoquants (so $m$ is concave). We can normalise this decomposition by assuming that $m(1,1)=1$.

It is helpful to think of $m(u, v)$ as the level of aggregate search activity in the market, and $\Phi(m)$ as converting activity into matching. Activity increases linearly with the stocks of searching workers and firms. We define the elasticity of matching with respect to activity, $\eta(m)$, and the average matching rate, $\phi(m)$, by:

$$
\eta(m) \equiv \frac{m \Phi^{\prime}(m)}{\Phi(m)} \quad \text { and } \quad \phi(m) \equiv \frac{\Phi(m)}{m}
$$

\footnotetext{
${ }^{3}$ Ex-ante heterogeneity or ex-ante investments can also lead to multiple equilibria in models with a constant-returns matching technology (Acemoglu, 1997, 2001; van den Berg, 2003).

${ }^{4}$ Homotheticity is an unimportant assumption for steady-state analysis but provides a mild simplification of the dynamic analysis. In particular, it admits a separation of scale and composition effects.
} 
The matching function has locally decreasing, constant, or increasing returns to scale when the elasticity $\eta$ is, respectively, less than, equal to, or greater than 1 . The average matching rate is a measure of the effectiveness of matching. For a constant returns matching function it is constant; otherwise $\phi(m)$ rises or falls where returns to scale are increasing or decreasing respectively. In the example in Figure 1a (see section 4.1), there are locally constant returns at $m^{c}$, where $\eta(m)=1$ and the average matching rate $\phi(m)$ is maximised; if $m<m^{c}$ there are increasing returns, the marginal matching rate is greater than the average matching rate, and $\eta>1$; above $m^{c}$ the converse conditions hold. Intuitively, $m^{c}$ is the point where search activity leads most effectively to matching.

Since activity $m(u, v)$ is homogeneous of degree 1 its elasticities with respect to unemployment and vacancies, denoted by $1-\alpha$ and $\alpha$ respectively, are functions only of market tightness, $\theta \equiv v / u$ (as are average and marginal activity with respect to $u$ and $v$ ). The elasticities of the matching rate $M=\Phi(m)$ with respect to $u$ and $v$ are:

$$
\eta_{u}=(1-\alpha) \eta \quad \text { and } \quad \eta_{v}=\alpha \eta
$$

The elasticity of substitution between $u$ and $v, \sigma=\left(m_{u} m_{v}\right) /\left(m_{u v} m\right)$, also depends on $\theta$ only, and is the same for $M$ and $m$. Define $\mu(\theta)$ as activity per worker, which also has elasticity $\alpha$ :

$$
\mu(\theta) \equiv m(1, \theta)
$$

Then the job-finding rate for workers, $\lambda$, which in the standard model depends on $\theta$ only, is proportional to the average matching rate:

$$
\lambda \equiv M / u=\phi(m) \mu(\theta)
$$

\subsection{Employment}

All agents are infinitely lived with common discount rate $\rho$. There are many firms, each with a single potential job, ${ }^{5}$ and a constant population of workers, with mass normalised to 1. At any instant a worker is either employed - matched to a firm - or unemployed and receiving unemployment income, which is normalised to zero.

A firm with no employee will create and maintain a vacancy whenever the present value of doing so is greater than zero. Thus the supply of vacancies is perfectly elastic at zero profit. While maintaining a vacancy the firm incurs a constant flow search cost $c$.

Match productivity is stochastic: an employed worker produces a constant flow of output $x$, which is a random variable realised when the worker and firm meet. A potential match is not necessarily consummated since if productivity is low the agents may prefer

\footnotetext{
${ }^{5}$ Equivalently, firms are of indeterminate size, with constant returns in production.
} 
to search for a better one. Match formation entails an instantaneous cost $K$, which is the same for every match and can be interpreted as a specific training cost. Matches are destroyed at constant rate $\delta$, in which case the worker searches for a new match, and the firm may create a new vacancy.

\subsection{The Match Surplus, and Surplus Sharing}

Consider a match that generates a flow of income $x$ while it lasts. If it is destroyed at time $t$ the worker obtains $V_{u}(t)$, the expected present value of his income while not employed, and the firm obtains zero (by the vacancy creation condition).

Let $Y(x, t)$ be the expected present value of the match at time $t$. We assume that matching decisions are privately efficient, so a potential match will be consummated if the initial surplus $Y-V_{u}$ exceeds the cost of match formation, $K$, and maintained thereafter until either $Y=V_{u}$, or it is exogenously destroyed. However, we will focus on equilibria in which matches are never endogenously destroyed: if the surplus is initially high enough that the match is worth forming, it will never fall to zero. ${ }^{6}$ The match value $Y$ satisfies:

$$
\rho Y=x+\delta\left(V_{u}-Y\right)+\frac{\partial Y}{\partial t}
$$

Since an increase in productivity would raise the income flow for the duration of the match, its effect on the match value is given by:

$$
\frac{\partial Y}{\partial x}=\frac{1}{\rho+\delta}
$$

A match will be consummated if and only if its initial value $Y\left(x, t_{0}\right)-K>V_{u}\left(t_{0}\right)$. Let $y$ be net productivity: $y \equiv x-(\rho+\delta) K$. Since $Y(x, t)-K \equiv Y(y, t)$, and $Y$ increases with productivity, it is acceptable if and only if net productivity $y$ exceeds the worker's reservation wage $z(t)$, which satisfies:

$$
Y(z, t)=V_{u}(t)
$$

We focus on net productivity: let $y$ have distribution function $G(y)$ and supremum $\bar{y}$. With reservation wage $z(t)$, the probability that a match is acceptable is:

$$
\pi(z) \equiv \mathrm{P}(y \geq z)=1-G(z)
$$

\footnotetext{
${ }^{6}$ This could be guaranteed by restricting the range of the distribution of match productivity $x$ to be less than $(\rho+\delta) K$. In fact, however, we need only that the change in the reservation wage on any equilibrium path is less than this bound - a much less stringent condition.
} 
The expected productivity of an acceptable match is given by:

$$
\mathrm{E}(y \mid y \geq z)=z+h(z) \text { where } h(z)=\frac{1}{\pi(z)} \int_{z}(1-G(y)) d y
$$

and the expected surplus from a meeting is: ${ }^{7}$

$$
\mathrm{E}[\max (Y(y)-Y(z), 0)]=\int_{z}(Y(y)-Y(z)) d G(y)=\frac{h(z) \pi(z)}{\rho+\delta} \equiv S(z)
$$

(where (3) is used to evaluate the integral). Note that $S(z)$ decreases with the reservation wage $z$. It is common in search models to assume that the distribution of productivity is log-concave, which guarantees that the flow surplus $h(z)$ also decreases with $z$. Here we impose only the weaker condition that $h(z)$ has elasticity less than one.

We do not model wage determination explicitly, but simply assume that if a match is consummated the worker and firm receive non-negative shares $\beta_{1}$ and $\beta_{2}$ respectively of the initial net surplus $Y(y)-V_{u}$. To allow for the possibility of an employment tax or subsidy, we do not assume that $\beta_{1}$ and $\beta_{2}$ sum to one. ${ }^{8}$

\subsection{Equilibrium Conditions}

For an unemployed worker, market opportunities depend on the job-finding rate $\lambda . V_{u}(t)$ satisfies:

$$
\rho V_{u}=\lambda \beta_{1} S(z)+\frac{d V_{u}}{d t}
$$

The reservation wage $z(t)$ satisfies (4) continuously, so:

$$
\frac{1}{\rho+\delta} \frac{d z}{d t}+\frac{\partial Y}{\partial t}=\frac{d V_{u}}{d t}
$$

Using (4), (6), and (2) evaluated at $z$, we can eliminate $V_{u}$ from (5) to obtain:

$$
z=\lambda \beta_{1} S(z)+\frac{\dot{z}}{\rho+\delta}
$$

and $\dot{z}$ denotes the derivative with respect to time.

A firm with a vacancy meets workers at rate $\lambda / \theta$; its expected surplus from a meeting with a worker with reservation wage $z$ is $\beta_{2} S(z)$. Free entry implies that the expected return to a vacancy is equal to the cost, so we have:

$$
\theta c=\lambda \beta_{2} S(z)
$$

\footnotetext{
${ }^{7}$ We suppress the time argument where it can be done without confusion.

${ }^{8}$ For example, if the surplus is taxed at rate $\tau$ and the remaining surplus is shared by Nash bargaining in which the worker has bargaining power $\beta$, we have $\beta_{1}=(1-\tau) \beta$ and $\beta_{2}=(1-\tau)(1-\beta)$.
} 
Finally unemployment evolves according to the difference between the inflow from employment as jobs are destroyed, and the outflow to employment, allowing for the reservation wage:

$$
\dot{u}=\delta(1-u)-\lambda \pi(z) u
$$

The market is fully described by equations (7), (8) and (9), where with non-constant returns the job-finding rate $\lambda$, defined by (1), varies with $u$ as well as $\theta$.

\subsection{Extensions: Participation and Search Intensity}

In an earlier working paper with non-constant returns in matching (Keller et al, 2007) we allowed also for endogenous entry and exit of workers, and search intensity: workers are heterogeneous in outside income and search only when it generates higher expected income. These assumptions permit the analysis of the joint dynamics of unemployment, participation and job-finding, and increase the potential for multiple equilibria. While the steady-state analysis is straightforward, heterogeneity introduces more complex individual dynamic behaviour, since workers with better outside options are less attached to the market and search less intensively. The assumption made here of a homogeneous labour force of fixed size makes the dynamic analysis more tractable, shifting the focus towards macroeconomic properties and facilitating comparison with the standard matching model.

\section{The Steady State}

A steady-state equilibrium $\left(z^{*}, \theta^{*}, u^{*}\right)$ satisfies:

$$
\begin{aligned}
z & =\lambda \beta_{1} S(z) \\
\theta c & =\lambda \beta_{2} S(z) \\
\Phi(m) \pi(z) & =\delta(1-u) \\
\text { where } \lambda \equiv \phi(m) \mu(\theta) & \text { and } \quad m \equiv u \mu(\theta)
\end{aligned}
$$

\subsection{Existence and Uniqueness of Equilibria}

To establish existence, we can eliminate $\theta$ from the steady-state equations to obtain a pair of equations in the reservation wage $z$ and market activity $m$ :

Lemma 1 In a steady state, $\theta=\left(\frac{\beta_{2}}{\beta_{1} c}\right) z$. Then for all $m \geq 0$ :

- (10) and (11) have a unique solution $z=\zeta_{1}(m) \in[0, \bar{y})$, where $\zeta_{1}^{\prime} \stackrel{\text { sgn }}{=} \eta(m)-1$; 
- (12) has a unique solution $z=\zeta_{2}(m)$, where $\zeta_{2}(0)=0, \zeta_{2}^{\prime}>0$, and $\zeta_{2}(\bar{m})=\bar{y}$ for some $\bar{m}<\infty$.

Proof: See Appendix.

The reservation wage that is optimal for individual agents, $z=\zeta_{1}(m)$, varies with market activity: it is determined by the average matching rate, $\phi(m)$. Since $z$ increases with $\phi(m)$, it rises or falls with market activity $m$ according to whether returns to scale in matching are increasing or decreasing. In the constant returns case there is a unique reservation wage, irrespective of the level of activity in the market. Equilibria are found at levels of market activity where this reservation wage is also consistent with constant unemployment: that is, where $\zeta_{1}(m)=\zeta_{2}(m)$. Both functions are continuous, and $\zeta_{2}(m)$ is strictly increasing. If the matching function has everywhere non-increasing returns to scale $\zeta_{1}(m)$ is non-increasing and there is a unique equilibrium; otherwise there may be several. By considering the properties of $\zeta_{1}$ and $\zeta_{2}$ we can show that:

Proposition 1 A steady-state equilibrium $\left(z^{*}, \theta^{*}, u^{*}\right)$ with activity $m^{*}>0$ exists for any $\beta_{1}, \beta_{2}>0$, provided that $\alpha \eta(0)<1$. It is unique if $\alpha \eta(m) \leq 1 \forall m$. If $\alpha \eta(0) \geq 1$ there is an equilibrium with no activity.

Proof: See Appendix.

Figure 1b illustrates possible equilibria for the matching function in Figure 1a, which has initially increasing and subsequently decreasing returns to scale. For this form of matching function, at most one equilibrium - the one with the highest activity level - can occur in the region of decreasing returns. More generally, the equilibrium with highest activity always occurs at a point where $\zeta_{2}^{\prime}>\zeta_{1}^{\prime}$. Note that, since $\zeta_{2}(m)$ is increasing, equilibria with higher activity levels have higher average matching rates and higher levels of worker income.

The sufficient condition for existence is quite standard: it is equivalent to the requirement that $M_{v}(1,0)=\infty$, which ensures that there are incentives for vacancy creation even when the market is small. If $\eta(0) \geq 1$ there is an equilibrium with no activity, and this may be the only equilibrium if $\alpha \eta(0) \geq 1$. The sufficient condition for uniqueness is obtained from a single-crossing condition: $\zeta_{2}^{\prime}>\zeta_{1}^{\prime}$ at any equilibrium where $m>0$ and $\eta(m) \leq 1 / \alpha$. The uniqueness condition may be compared with the result of Burdett and Wright (1998) that with fixed and identical numbers of workers and firms, log-concavity of the productivity distribution is sufficient to guarantee uniqueness with increasing returns. Here log-concavity is not enough: when agents are able to respond to market conditions we need an upper bound on the degree of returns to scale. In the extension of the model 

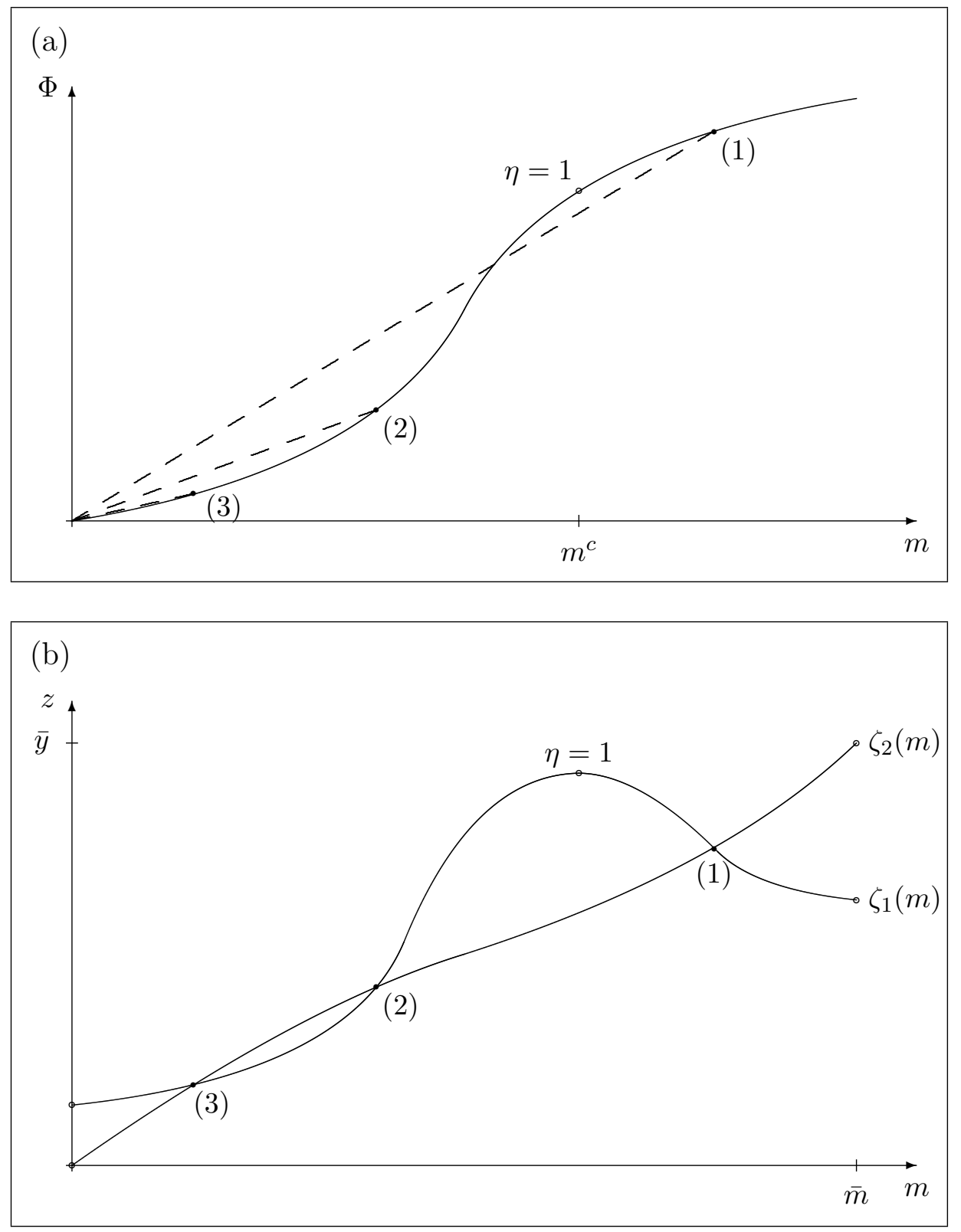

Figure 1: A matching function with initially increasing and then decreasing returns, and three steady state equilibria. Panel (a) shows the matching rate $\Phi(m)$ as a function of market size, $m$; panel (b) shows the equilibria in $(m, z)$ space $(z=$ reservation wage).

with endogenous participation of workers as well as firms (see section 3.5), the bound becomes more restrictive; endogenous search intensity reduces it still further. Thus the more agents are able to respond to changes in market conditions, the more likely are multiple equilibria.

\subsection{Stability}

We have used the conventional assumption that the number of vacancies is determined by a zero-profit condition, with the implicit underlying assumption that profits would fall 
if more firms were to enter, and rise if firms left. However, we need to ensure that this holds - that is, that the state-state equilibrium is stable with respect to vacancy creation. This requires a bound on the rate of increasing returns at the equilibrium:

Proposition 2 A steady-state equilibrium with activity $m>0$ is stable with respect to vacancy creation if and only if $\alpha \eta(m)<1$. An equilibrium with zero activity is stable (unstable) if $\alpha \eta(0)>(<) 1$.

Proof: In a steady-state equilibrium the total profit flow, $\Pi=\Phi(m) \beta_{2} S(z)-c v$, is zero. Suppose that $v$ increases instantaneously by $d v$. This has no effect on $u$, or on reservation wages $z$ because agents expect to be in equilibrium in future when matches are formed. The effect on profit is:

$$
\begin{aligned}
d \Pi & =\eta \alpha \beta_{2} S(z) \frac{\Phi(m)}{v} d v-c d v \\
& = \begin{cases}(\eta \alpha-1) c d v & \text { if } v>0 \\
\eta \alpha \beta_{2} S(z) \lim _{v \rightarrow 0}\left(\frac{\Phi(m)}{v}\right) d v-c d v & \text { if } v=0\end{cases}
\end{aligned}
$$

So an equilibrium with $m>0$ is stable if and only if $\eta \alpha<1$. The stability of an equilibrium at zero depends on the limit of $\Phi(m) / v$ : if $\eta(0) \alpha<1$, this limit is infinite, so the equilibrium is unstable; if $\eta(0) \alpha>1$, the limit is zero and it is stable. (If $\eta(0) \alpha=1$ the limit is finite and positive - then stability depends on the parameters.)

Thus stability requires decreasing returns to vacancy creation. ${ }^{9}$ An implication of Proposition 2 is that, if we have multiple equilibria numbered in order of decreasing market size as in Figure 1, even-numbered equilibria are unstable: at such points $\zeta_{2}^{\prime}<\zeta_{1}^{\prime}$, which from the proof of Proposition 1 implies that $\eta \alpha>1$. Hence (2) is unstable; (1) is stable since it has decreasing returns, and (3) is stable if returns are not rapidly increasing there.

\subsection{Steady-State Welfare}

In a steady-state equilibrium social welfare $\Omega$, which we take to be the present value of aggregate net income, is given by the flow of output less the cost of vacancies:

$$
\rho \Omega=(1-u)(z+h(z))-u \theta c
$$

\footnotetext{
${ }^{9}$ As discussed in the previous section, endogenous participation or search intensity would make the market more responsive to vacancy creation, reducing the required upper bound and hence the likelihood of stable equilibria with increasing returns.
} 
We will now show that, if there are multiple equilibria, they are welfare-ranked by market size, $m$. This is not surprising in the case where the matching function has everywhereincreasing returns, since agents' payoffs are then increasing in the search activity of others. Cooper and John (1988) showed that this property, which they called positive spillovers, implies Pareto-ranking in static symmetric coordination games; Cooper (1999) showed that multiple equilibria are Pareto-ranked in Diamond's (1982) search model with increasing returns. Our result is stronger: even in the absence of strategic complementarity and positive spillovers - that is, whatever the shape of the matching function - multiple equilibria can be ranked.

Intuitively, equilibria with higher $m$ have a higher aggregate matching rate $\Phi$, so require a higher reservation wage $z$ to satisfy the steady-state condition. For individuals to choose a high $z$, the average matching rate $\phi$ must be high - and a high $\phi$ is good for welfare. $^{10}$ To see the result formally, assume for ease of comparison with other results that there are no taxes or subsidies $\left(\beta_{1}+\beta_{2}=1\right)$. Then using the equilibrium conditions welfare can be written:

$$
\rho \Omega=z+\frac{\rho}{\delta} \Phi(m) S(z)
$$

The first term is the flow welfare of the unemployed; the second is the aggregate surplus. As $m$ increases, the optimal response $z=\zeta_{1}(m)$, and hence the welfare of an unemployed worker, rises or falls depending on returns to scale. It can be shown that the average expected surplus, $\phi S$, moves in the same direction as $z$. However, if we compare welfare at two equilibria, we can see that both terms in the above expression are higher at the one with the larger market. First, from the steady-state condition $z=\zeta_{2}(m)$ we know that the welfare of an unemployed worker, $z$, is higher. For the second term, it is shown in the Appendix that when $z$ is optimally chosen the aggregate surplus $\Phi(m) S(z)$ increases with $m$ : the rise in $m$ always outweighs any fall in the average surplus. Hence we have:

Proposition 3 When multiple equilibria exist, steady-state welfare increases with equilibrium market size.

The result can be extended to the case with $\beta_{1}+\beta_{2} \neq 1$, when welfare is:

$$
\rho \Omega=z+\Phi(m) S(z)\left(\frac{\rho}{\delta}+1-\left(\beta_{1}+\beta_{2}\right)\right)
$$

Note that the original expression for $\Omega$ does not depend on $\beta_{1}$ or $\beta_{2}$. Although we allow $\beta_{1}+\beta_{2} \neq 1$, the corresponding tax or subsidy is assumed to be implemented as a transfer between agents within the model: for example, since workers earn rents in equilibrium,

\footnotetext{
${ }^{10}$ Applying exactly the same intuition it can be shown that the ranking of equilibria in the Diamond model generalises to the case where returns to scale are not everywhere increasing.
} 
an employment subsidy could be financed by a lump-sum tax on workers. A tax or subsidy thus has no direct effect on aggregate income; $\beta_{1}+\beta_{2}$ appears here only because it determines the equilibrium values of $z, u$ and $\theta$, and hence affects welfare indirectly. Then, applying the same argument as before, a sufficient condition for multiple equilibria to be welfare-ranked is that the employment subsidy is not too high: $\beta_{1}+\beta_{2} \leq 1+\rho / \delta$.

\section{Local and Global Dynamics}

\subsection{Saddle Path Stability}

The complete dynamic system obtained in section 3.4 can be written in terms of $u$ and $z$ :

$$
\begin{aligned}
\dot{u} & =F_{1}(u, z) \equiv \delta(1-u)-\lambda u \pi(z) \\
\dot{z} & =F_{2}(u, z) \equiv(\rho+\delta)\left(z-\beta_{1} \lambda S(z)\right)
\end{aligned}
$$

The job-finding rate $\lambda$ is determined by the zero-profit condition:

$$
\begin{aligned}
& \theta c=\lambda \beta_{2} S(z) \\
& \text { where } \quad \lambda \equiv \phi(m) \mu(\theta) \quad \text { and } \quad m \equiv u \mu(\theta)
\end{aligned}
$$

and hence can be written as a function of $u$ and $z$ :

Lemma 2 If $\eta(m) \alpha \neq 1$, equations (16) and (17) determine $\lambda$ as an implicit function of $z$ and $u$ for $z \in[0, \bar{y}]$ and $u \in(0,1]$ :

$$
\lambda=\Lambda(u, z) \quad \text { where } \quad \frac{u}{\lambda} \frac{\partial \Lambda}{\partial u}=-\frac{1-\eta}{1-\eta \alpha}, \quad \frac{1}{\lambda} \frac{\partial \Lambda}{\partial z}=-\frac{\eta \alpha}{1-\eta \alpha} \frac{1}{h(z)}
$$

Proof: See Appendix.

Note, however, that this is only valid in regions of $u$ - $z$ space where $\eta(m) \alpha \neq 1$. The following analysis therefore applies globally only if $\eta(m) \alpha<1$ for all $m$; but it applies locally at any steady state that is stable with respect to vacancy creation (section 4.2), since we know that this condition holds there. The Jacobian matrix is:

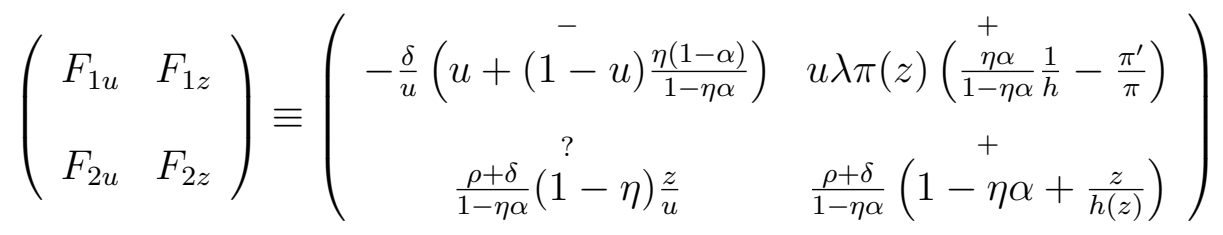


from which we can construct a phase diagram for $u \in(0,1]$ and $z \in[0, \bar{y}]$. The slopes and boundary conditions for the lines $\dot{u}=0$ and $\dot{z}=0$ are:

- $\dot{u}=0: \frac{d z}{d u}=-\frac{F_{1 u}}{F_{1 z}}>0 ; z\left(u_{0}\right)=0$ where $u_{0} \in(0,1) ; z(1)=\bar{y}$.

- $\dot{z}=0: \frac{d z}{d u}=-\frac{F_{2 u}}{F_{2 z}} \stackrel{s g n}{=} 1-\eta ; z(0)=\left\{\begin{array}{ll}0 \\ z_{0} \in(0, \bar{y}) & \text { if } \eta(0) \stackrel{>}{=} 1 \\ \bar{y} & <\end{array}\right\} ; z(1)=z_{1} \in(0, \bar{y})$.

We can now show (and it is straightforward to see from the phase diagram) that any steady state $\left(u^{*}, z^{*}\right)$ where $\eta \alpha<1$ is saddle-path stable; $u$ is the state variable and the reservation wage $z$ is the jump variable. The saddle path $z(u)$ satisfies:

$$
\frac{d z}{d u}=\frac{F_{2}(u, z)}{F_{1}(u, z)}, \quad z\left(u^{*}\right)=z^{*}
$$

In the neighbourhood of the steady state the properties of the system are determined by the matrix (19), evaluated at $\left(u^{*}, z^{*}\right)$. We can confirm saddle-path stability by verifying that the determinant $\Delta \equiv F_{1 u} F_{2 z}-F_{2 u} F_{1 z}$ is negative. The slope of the saddle path is the slope of the eigen vector corresponding to the negative eigen value; this depends on the sign of $F_{2 u}$ and therefore on returns to scale. Furthermore if $\alpha \eta<1$ everywhere, $F_{1}$ and $F_{2}$ are continuous and $(20)$ has a continuous solution on $(0,1]$. Thus we have:

Proposition 4 A steady state $\left(u^{*}, z^{*}\right)$ is locally saddle-path stable if $\alpha \eta\left(m^{*}\right)<1$. The saddle path is locally downward-sloping in $u$-z space if $\eta<1$, flat if $\eta=1$, and upwardsloping if $\eta>1$. If $\alpha \eta(m)<1$ for all $m$ it is globally saddle-path stable and the saddle path is continuous on $(0,1]$.

Proof: See Appendix.

Figure 2 illustrates the shapes of the saddle paths for two cases in which the matching function satisfies the condition for global stability and has initially increasing and subsequently decreasing returns to scale. The steady state is unique and stable; in case (a) it is in a region of decreasing returns and in case (b) it is in a region of increasing returns. Note that in both cases the slope of the saddlepath at any point does not depend only on whether returns to scale are increasing or decreasing at that point, since forward-looking agents anticipate the future path of the market when choosing the reservation wage. Suppose, for example, that in case (a) the market begins at a point where unemployment is low. As market size increases, matching efficiency improves since $\eta>1$, and the reservation wage initially rises. Thus the saddle path is initially upward sloping, but then it begins to slope down while returns to scale are still increasing: agents lower their reservation wage in anticipation of entering the region of decreasing returns. 

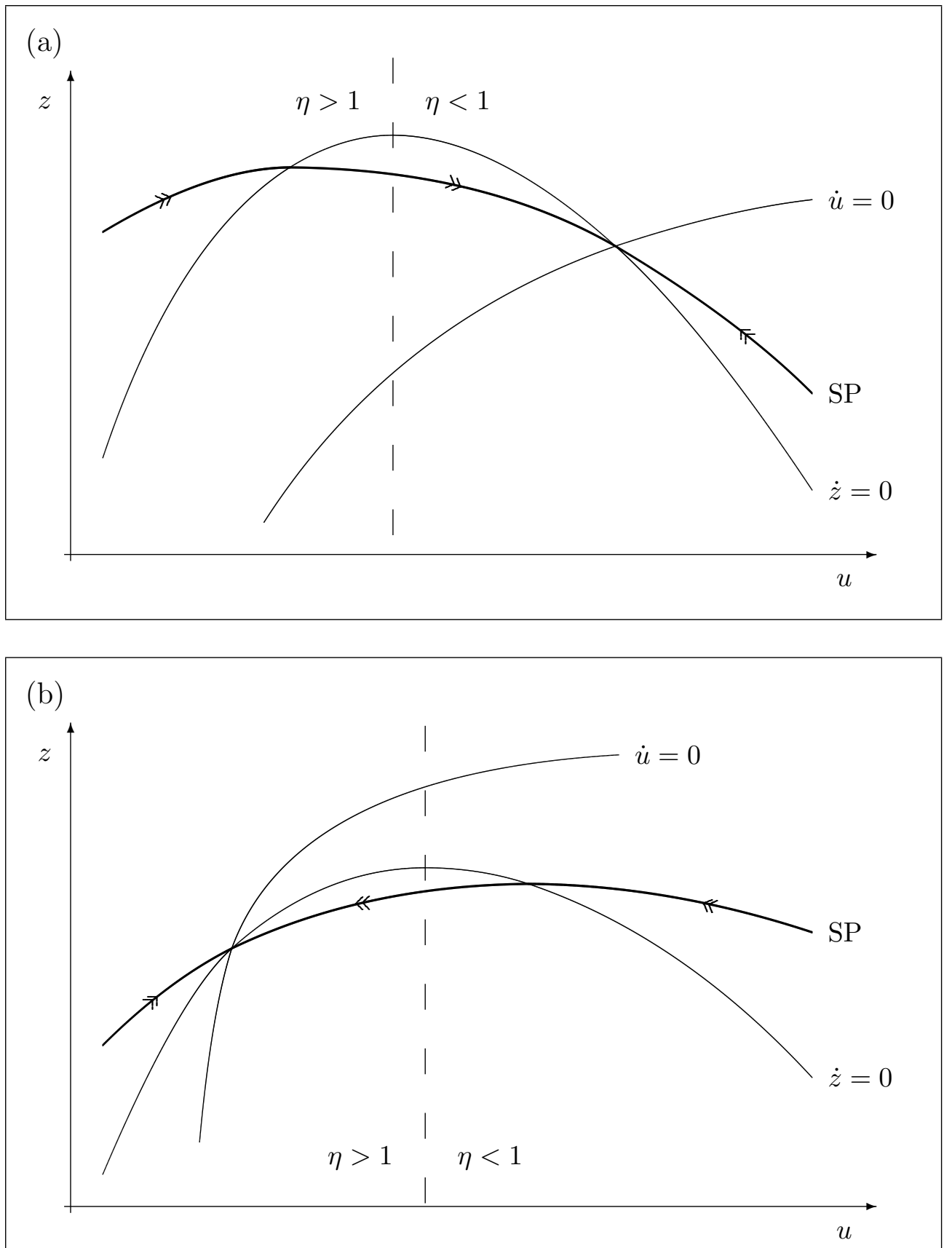

Figure 2: Saddle paths in $(z, u)$ space for a matching function with initially increasing and then decreasing returns, and a unique globally stable steady state. In case (a) the steady state lies in a region of decreasing returns; in case (b) it is in a region of increasing returns. ( $z=$ reservation wage; $u=$ unemployment rate.)

\subsection{Dynamic Adjustment}

In the neighbourhood of a stable steady state, the market converges along the saddle path at rate $\nu$, where $\nu$ is the negative eigen value of the matrix (19), satisfying:

$$
\nu^{2}-\nu X+\Delta=0 \quad \text { where } \quad X=F_{1 u}+F_{2 z}
$$


Compared with the standard constant returns case, the speed of adjustment $|\nu|$ is higher under increasing returns and lower under decreasing returns:

Proposition 5 The speed of market adjustment $|\nu|$ is $\delta+\lambda \pi$ under constant returns to scale, and increases with returns to scale $\eta: \frac{\partial|\nu|}{\partial \eta}>0$.

Proof: See Appendix.

We can now describe the behaviour of the labour market variables as the economy adjusts along the saddle path. Suppose, for example, that the economy is in steady state at an equilibrium with decreasing returns, and an unexpected temporary job destruction shock raises unemployment. The increase in market activity makes matching less efficient - the job-finding rate $\lambda$ falls. The economy moves instantaneously onto the saddle path, as workers lower their reservation wage, and firms create more vacancies; however market tightness falls.

As unemployment decreases back to its steady-state level over time, firms reduce vacancies, and the reservation wage rises; the effectiveness of matching improves as market tightness and the job-finding rate rise. While unemployment is high, output per employee is below its steady-state level because less productive matches are formed.

The directions of these changes are confirmed in the proof of the following results:

Proposition 6 In the neighbourhood of an equilibrium with decreasing (increasing) returns, market tightness, the job-finding rate, and the reservation wage vary negatively (positively) with unemployment; vacancies vary positively but less (more) than under constant returns.

Proof: See Appendix.

Proposition 6 suggests that decreasing returns in matching could help to explain the procyclicality of market tightness and the job-finding rate documented by Shimer (2005) for US data. With constant returns, movements in the job-finding rate can only be interpreted as shifts of the steady state, but with decreasing returns the job-finding rate varies negatively with unemployment during periods of dynamic adjustment. A low jobfinding rate and market tightness may be attributed, at least in part, to the fact that unemployment is high, rather than to low productivity - and average productivity may itself be negatively affected by the congested labour market. Note, however, that the responsiveness of vacancies to unemployment, although reduced by decreasing returns, remains positive. Shimer's finding that productivity shocks are required to generate a Beveridge curve remains true here. 
Our results also suggest a different perspective on those of Hall (2005). He estimates the "equilibrium" unemployment rate at time $t$ by $u_{t}^{*}=\delta /\left(\delta+\lambda_{t}\right)$ where $\lambda_{t}$ is the current job-finding rate (assuming $\pi=1$ ). With constant returns to scale in matching, $u_{t}^{*}$ is the current steady state, so he interprets his finding that actual unemployment $u_{t}$ closely tracks $u_{t}^{*}$ as suggesting that - because the inflow and outflow rates are high - dynamic adjustment is irrelevant. But with decreasing returns, $\lambda$ is not constant, and $u_{t}^{*}$ is not a steady state. If unemployment is above its steady-state level, $\lambda$ is low and $u_{t}^{*}$ is above steady-state unemployment. In the return to the steady state, $u_{t}$ and $u_{t}^{*}$ fall together. This provides some intuition for Proposition 5: convergence is slower with decreasing returns because the "short-run equilibrium" $u_{t}^{*}$ rises and falls with level of unemployment.

\subsection{The Implications of Decreasing Returns: Simulations}

The qualitative analysis in the previous section suggests that decreasing returns in matching could contribute to an explanation of the business cycle dynamics of unemployment and the job-finding rate: the market adjusts more slowly, and dynamic adjustment is accompanied by variation in market tightness and the job-finding rate. In this section we examine the quantitative implications of decreasing returns.

\subsubsection{Calibration}

\begin{tabular}{ccl}
\hline \hline Parameter & Value & Description \\
$\beta_{1}$ & 0.5 & Share of surplus accruing to worker \\
$\beta_{2}$ & 0.5 & Share of surplus accruing to firm \\
$\delta$ & 0.02 & Job separation rate \\
$\rho$ & 0.005 & Discount rate \\
$\bar{y}$ & 1 & Productivity is uniformly distributed on $[0, \bar{y}]$ \\
$\Phi_{0}(1)$ & 1 & Scalar on matching function when $\eta=1$ \\
$\alpha$ & 0.5 & Elasticity of activity with respect to unemployment \\
$\eta$ & $\{1,0.9,0.8 .0 .7,0.6,0.5\}$ & Elasticity of matching with respect to activity \\
\hline \hline
\end{tabular}

Table 1: Parameter values for the monthly calibration of the decreasing returns model

The model is calibrated at a monthly frequency, with a job separation rate of $2 \%$ per month and a discount rate of $0.5 \%$ per month. The matching function has constant elasticity with respect to aggregate search activity: $\Phi(m)=\Phi_{0} m^{\eta}$, and the elasticity, $\eta$, is varied between 1 (constant returns) and 0.5 (capturing rapidly diminishing returns). 
The match surplus is shared equally between the worker and firm, and is neither taxed nor subsidised. The elasticity of aggregate matching activity with respect to unemployment, $\alpha$, is set to a half so that (as is conventional) the Hosios condition holds under constant returns. ${ }^{11}$ Net match productivity is uniformly distributed on $[0, \bar{y}]$. The parameters $\bar{y}$ and $\Phi_{0}$ are chosen to ensure that, in the case $\eta=1$, we have a reasonable equilibrium unemployment rate of around $7.5 \%$, and a job-finding rate which remains below 1. Then, $\Phi_{0}$ is varied with $\eta$ so that the equilibrium is the same for all values of $\eta$ (specifically, $\Phi_{0}(\eta)=\Phi_{0}(1)\left(m^{*}\right)^{1-\eta}$ where $m^{*}$ is steady-state search activity). Table 1 lists the parameters, and Table 2 shows the steady state.

\begin{tabular}{cccccccc}
\hline \hline $\begin{array}{c}\text { unemployment } \\
\text { rate }\end{array}$ & $\begin{array}{c}\text { matching } \\
\text { rate }\end{array}$ & $\begin{array}{c}\text { reservation } \\
\text { wage }\end{array}$ & $\begin{array}{c}\text { job-finding } \\
\text { rate }\end{array}$ & $\begin{array}{c}\text { market } \\
\text { tightness }\end{array}$ & vacancies & $\begin{array}{c}\text { acceptance } \\
\text { probability }\end{array}$ & surplus \\
$u$ & $\Phi(m)$ & $z$ & $\lambda$ & $\theta$ & $v$ & $\pi(z)$ & $S(z)$ \\
0.0756 & 0.0637 & 0.7097 & 0.8425 & 0.7097 & 0.0537 & 0.2903 & 1.6849 \\
\hline \hline
\end{tabular}

Table 2: Steady-state values of endogenous variables (for all values of $\eta$ )

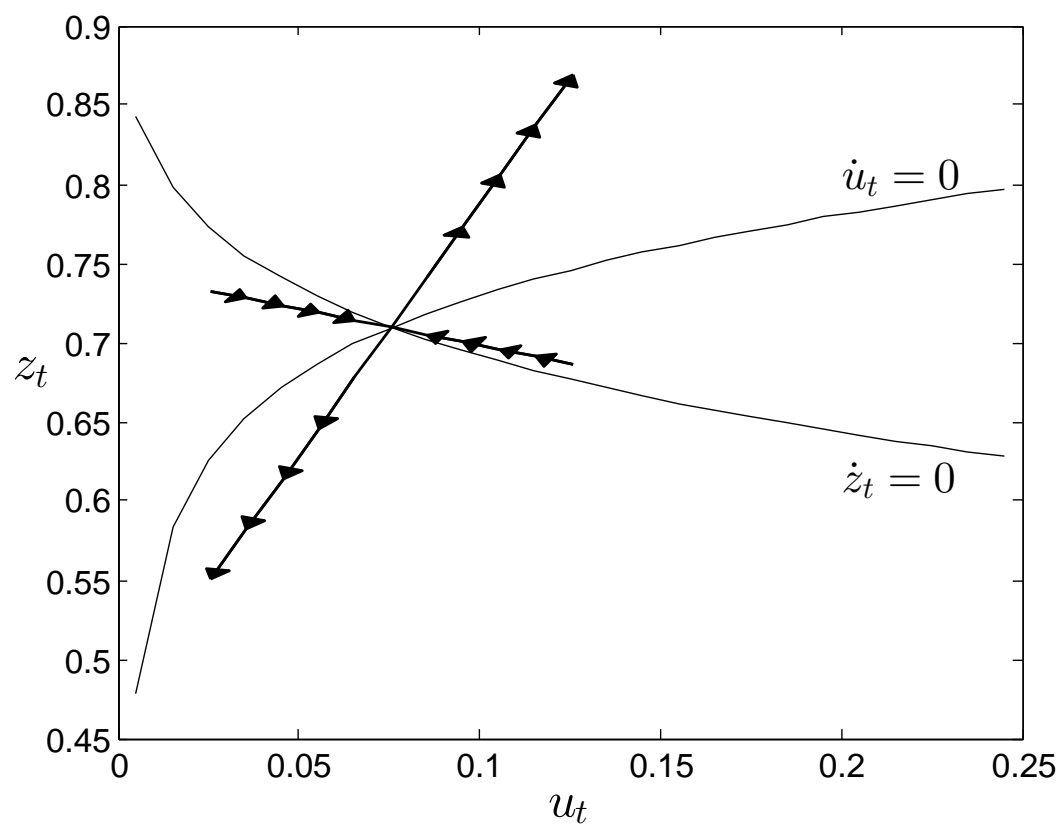

Figure 3: Phase diagram for the calibrated model with $\eta=0.5$

The phase diagram for the case $\eta=0.5$ is shown in Figure 3. The saddle path is downward-sloping, but relatively flat even in this case of rapidly diminishing returns: $\frac{d z}{d u}=-0.4621$, implying that the reservation wage is not very responsive to changes in

\footnotetext{
${ }^{11}$ Note that the Hosios condition cannot be imposed when $\eta<1$; in the last section of this paper we show that a generalisation of the Hosios condition is required for efficiency under non-constant returns.
} 
unemployment - the elasticity is approximately 0.05. This feature appears to be robust across different calibrations of the model. It suggests that agents lower reservation wages rather little in the face of poor market conditions, because it incorporates their expectations of future improvement. As we demonstrate in the simulations that follow, a rise in unemployment is therefore reflected more in falls in market tightness and the job-finding rate, and the wage is not very responsive.

\subsubsection{Impulse response functions}

Impulse response functions describe how the economy returns to equilibrium along the saddle path. The speed of convergence back to steady state depends on the stable root $\nu$ of the dynamic system when linearised around the steady state (equation (21)).

\begin{tabular}{rcccccc}
\hline \hline & $\eta=1$ & $\eta=0.9$ & $\eta=0.8$ & $\eta=0.7$ & $\eta=0.6$ & $\eta=0.5$ \\
Stable root, $\nu$ & -0.2645 & -0.2349 & -0.2095 & -0.1874 & -0.1680 & -0.1506 \\
Implied persistence, $e^{\nu}$ & 0.7676 & 0.7906 & 0.8110 & 0.8291 & 0.8454 & 0.8602 \\
\hline \hline
\end{tabular}

Table 3: Rate of convergence to steady state

The implied persistence is the exponential of the stable root, and describes the $\operatorname{AR}(1)$ persistence of variables as they return to steady state. Table 3 shows that persistence increases as $\eta$ falls (Proposition 5).

Figure 4 confirms this by illustrating how unemployment rises and then returns to steady state following a temporary shock to the job separation rate. The shock is set to increase the separation rate by 1.08 percentage points for a single period, implying an initial increase in unemployment of one percentage point irrespective of returns to scale (since the steady state is the same in each case). With decreasing returns to scale, matching is less effective when unemployment is high. Hence lower values of $\eta$ imply that vacancies rise less, and the job-finding rate falls more, in response to the initial shock, slowing the subsequent reduction of unemployment. The return to steady state is slower the more returns are decreasing. Excess unemployment halves in 2.6 months under constant returns, but when $\eta=0.5$ this takes 4.6 months.

\subsubsection{Simulation}

The model as it stands is completely deterministic. We now present a simulation of the effects of shocks to the job separation rate $\delta$, accurate to first order (see Schmitt-Grohe and Uribe, 2004, Theorem 1). We assume that the shock is iid normal; the choice of the 

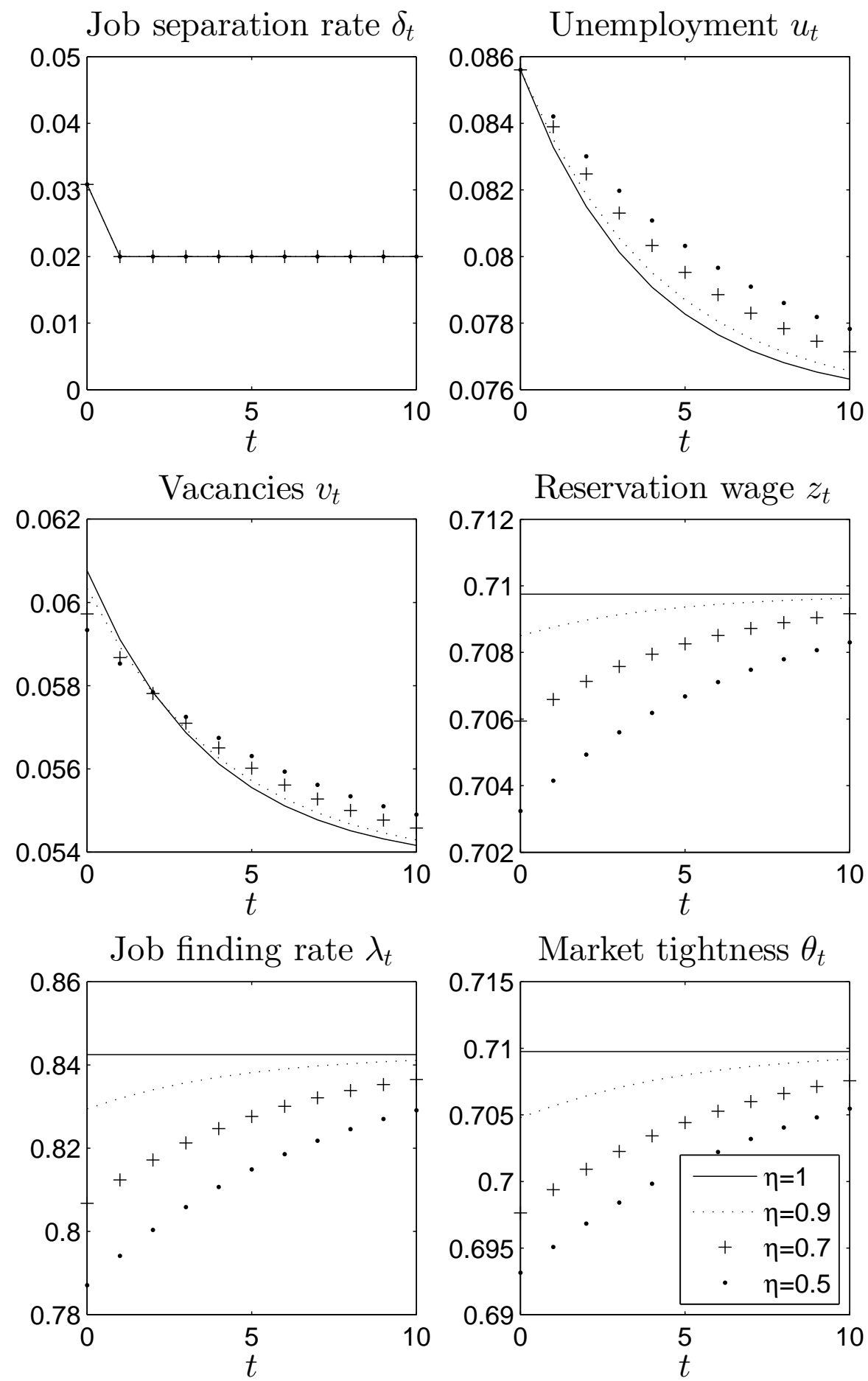

Figure 4: Impulse response functions for a temporary shock to the separation rate that raises unemployment by 1 percentage point 
variance is just a normalisation, because the model only ties down relative variances. We set it to normalise the standard deviation of $\ln u$ to 1 when $\eta=1$. With constant returns $\ln v$ and $\ln m$ also have standard deviations equal to 1 , and other variables remain constant. Table 4 shows the standard deviations of the logs of all variables for different values of $\eta$, relative to the constant returns benchmark. We know that under decreasing returns, matching efficiency changes with unemployment, moderating the response of vacancies so that market tightness and job-finding become effectively procyclical; here we see that they exhibit substantial variation. Since the reservation wage $z$ is determined by forwardlooking expectations it varies less, so the wage remains relatively insensitive to changing labour market conditions. Unemployment is more variable under decreasing returns: the procyclical job-finding rate slows convergence (as in Figure 4) and thus amplifies the effect on unemployment of successive shocks to the separation rate.

\begin{tabular}{rccccccc}
\hline \hline & & $\eta=1$ & $\eta=0.9$ & $\eta=0.8$ & $\eta=0.7$ & $\eta=0.6$ & $\eta=0.5$ \\
unemployment & $u$ & 1 & 1.0477 & 1.0972 & 1.1488 & 1.2031 & 1.2606 \\
market activity & $m$ & 1 & 0.9964 & 0.9994 & 1.0082 & 1.0227 & 1.0427 \\
matching rate & $\Phi(m)$ & 1 & 0.8968 & 0.7995 & 0.7057 & 0.6136 & 0.5214 \\
reservation wage & $z$ & 0 & 0.0099 & 0.0209 & 0.0331 & 0.0468 & 0.0621 \\
job-finding rate & $\lambda$ & 0 & 0.1510 & 0.2977 & 0.4431 & 0.5895 & 0.7392 \\
market tightness & $\theta$ & 0 & 0.1027 & 0.1957 & 0.2812 & 0.3608 & 0.4357 \\
vacancies & $v$ & 1 & 0.9451 & 0.9015 & 0.8676 & 0.8423 & 0.8249 \\
acceptance probability & $\pi(z)$ & 0 & 0.0242 & 0.0510 & 0.0809 & 0.1143 & 0.1518 \\
match surplus & $S(z)$ & 0 & 0.0483 & 0.1020 & 0.1619 & 0.2287 & 0.3035 \\
wage & $w$ & 0 & 0.0067 & 0.0142 & 0.0225 & 0.0318 & 0.0422 \\
\hline \hline
\end{tabular}

Table 4: Standard deviations of simulated variables (in logs)

Note that the variability of the activity rate $m$ is not monotonic in $\eta$. When $\eta$ is just below 1 , rapid convergence means that the forward-looking reservation wage $z$ responds very little to changes in unemployment. So the fall in matching efficiency is reflected mainly in vacancy creation, and the decreased variability of vacancies dominates the increased variability of unemployment in the overall variability of market activity. But when $\eta$ is very low, convergence is slower and $z$ does respond, partially offsetting the effect of unemployment on the incentive to create vacancies; then, the increased variability of unemployment dominates in the variability of $m$.

We would not expect a model with separation shocks alone to generate the volatility we see in the data, but this exercise demonstrates that decreasing returns does contribute 


\begin{tabular}{|c|c|c|c|c|c|c|c|c|c|c|c|c|c|c|}
\hline & \multicolumn{7}{|c|}{$\eta=1$} & \multicolumn{7}{|c|}{$\eta<1$} \\
\hline & $m$ & $z$ & $\lambda$ & $\theta$ & $v$ & $\pi$ & $w$ & $m$ & $z$ & $\lambda$ & $\theta$ & $v$ & $\pi$ & $w$ \\
\hline unemployment $u$ & + & 0 & 0 & 0 & + & 0 & 0 & + & - & - & - & + & + & - \\
\hline market activity $m$ & & 0 & 0 & 0 & + & 0 & 0 & & - & - & - & + & + & - \\
\hline reservation wage $z$ & & & 0 & 0 & 0 & 0 & 0 & & & + & + & - & - & + \\
\hline job finding rate $\lambda$ & & & & 0 & 0 & 0 & 0 & & & & + & - & - & + \\
\hline market tightness $\theta$ & & & & & 0 & 0 & 0 & & & & & - & - & + \\
\hline vacancies $v$ & & & & & & 0 & 0 & & & & & & + & - \\
\hline acceptance probability $\pi$ & & & & & & & 0 & & & & & & & - \\
\hline
\end{tabular}

Table 5: Cross correlations of simulated variables

appreciable variation. As a rough comparison, Shimer (2005) reports for detrended US data (with all variables in logs) that the standard deviations of market tightness $(\theta)$ and job-filling (corresponding to $\lambda \pi$ rather than $\lambda$ ) are respectively about 2 and 0.6 times that of $u$, and in his simulations with a constant-returns matching function separation shocks generate almost no variation in these variables. Here, separation shocks imply no variation at all in $\theta$ and $\lambda \pi$ under constant returns, but with $\eta=0.7$ the standard deviations of $\ln \theta$ and $\ln (\lambda \pi)$ are respectively 0.24 and 0.32 times that of $\ln u$. This suggests that introducing a plausible degree of decreasing returns into the matching function would be a straightforward modification that would help to reconcile empirical matching models with labour market evidence, enhancing the procyclicality of both job-finding and market tightness typically generated by productivity shocks.

This is a linear system with only one state variable, unemployment. Each of the endogenous variables is a linear function of the single state variable, so all variables are perfectly correlated and have the same persistence. There is therefore no point in reporting the value of cross correlations, but Table 5 shows which variables are positively, negatively, or not correlated, confirming the theoretical results in Proposition 6.

\subsection{Dynamics with Multiple Equilibria}

With multiple rational expectations equilibria, agents face a coordination problem. In addition to the saddle-path stability condition, stability of a steady-state equilibrium requires that all agents expect the market to return to this steady state. Where there are several stable steady states, it is possible that any one of them can be reached from a given initial position, if agents believe that it will be.

To illustrate this property in a simple special case, suppose that the average matching 
rate is either high or low depending on the level of market activity:

$$
\Phi(m)=\left\{\begin{array}{ll}
\phi_{\ell} m & \text { if } m \leq \tilde{m} \\
\phi_{h} m & \text { otherwise }
\end{array} \quad \text { where } \phi_{\ell}<\phi_{h}\right.
$$

For a given average matching rate $\phi$, the steady-state equations (10) to (13) have a solution:

$$
z=z(\stackrel{+}{\phi}), \theta=\theta(\stackrel{+}{\phi}), \lambda=\phi \mu(\theta), u=\frac{\delta}{\delta+\lambda}, m=u \mu(\theta)
$$

So we have two possible stable steady states $\left(z_{i}, \theta_{i}, u_{i}\right)$ corresponding to the two levels of the average matching rate $\phi_{i}$; an equilibrium with a high (low) level of $\phi$ exists if the corresponding activity level $m$ is above (below) $\tilde{m}$. The equilibrium with higher average matching rate has higher income, tightness and activity, and lower unemployment. If:

$$
\frac{\delta \mu\left(\theta_{\ell}\right)}{\delta+\lambda_{\ell}}<\tilde{m}<\frac{\delta \mu\left(\theta_{h}\right)}{\delta+\lambda_{h}}
$$

we have multiple equilibria, and in the welfare-superior high-activity equilibrium firms create more jobs because other firms do so and the average matching rate is high. ${ }^{12}$

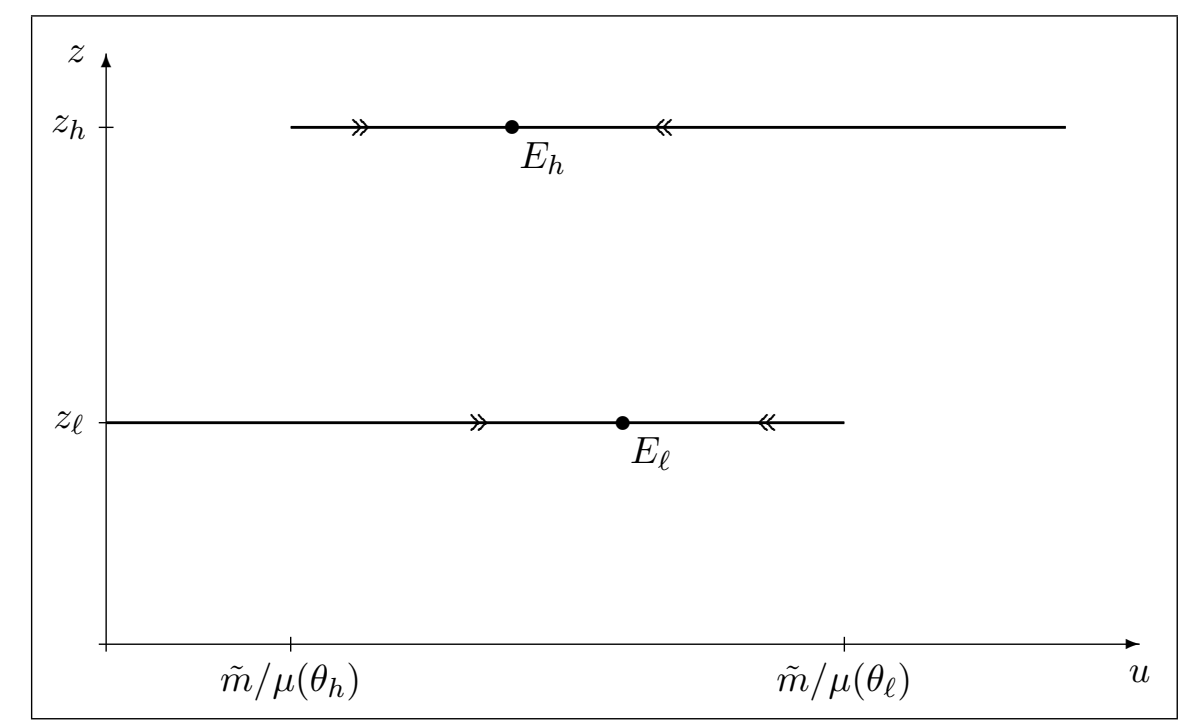

Figure 5: Multiple equilibria and saddle paths for the special case $\phi(m)=\left\{\begin{array}{ll}\phi_{\ell} & m \leq \tilde{m} \\ \phi_{h} & m>\tilde{m}\end{array}\right.$. Equilibrium $E_{h}$ has higher activity, higher market tightness $\theta_{h}$ and lower unemployment.

\footnotetext{
${ }^{12}$ Note, however, that market activity $m=u \mu(\theta)$ is more responsive to unemployment than tightness, and the equilibrium with higher activity must have lower unemployment. Hence multiple equilibria are possible in this simple model only for parameters such that both the level of unemployment and the elasticity of activity with respect to tightness are relatively high. If activity were also affected by participation and search intensity (see section 3.5), multiple equilibria could occur for a wider range of parameters.
} 
Within the regions of high and low activity the average matching rate is constant it does not vary with market size. Hence the dynamic system behaves like the constant returns model, with a horizontal saddle path. ${ }^{13}$ Figure 5 shows the saddle paths when there are multiple equilibria. When unemployment $u$ lies between $\tilde{m} / \mu\left(\theta_{h}\right)$ and $\tilde{m} / \mu\left(\theta_{l}\right)$, the market can jump onto either saddle path. For example, if agents expect to reach the high activity equilibrium, firms create vacancies so that $\theta=\theta_{h}$. Then activity $m=u \mu\left(\theta_{h}\right)$, which lies above $\tilde{m}$ so expectations are fulfilled.

\section{Efficiency}

It is well known that with constant returns to scale in matching, the decentralised matching market is efficient (subject to matching frictions) under the Hosios condition: when the surplus shares $\beta_{1}$ and $\beta_{2}$ are equal to the elasticities of matching with respect to unemployment and vacancies. This gives individual agents the right incentives to ensure that search externalities are internalised, and hence maximise total output net of search costs. Thus it is possible, in principle, for a market in which wages are determined by ex-post bargaining between worker and firm to achieve efficiency, although in practice there is no reason to expect the condition to be satisfied.

In this section we determine the social planner's optimum for the matching model with non-constant returns and derive a simple generalisation of the Hosios condition.

\subsection{The Social Planner's Problem}

Consider a social planner who wishes to maximise the present value of aggregate net income, continuously determining the number of vacancies (or equivalently market tightness), and the reservation productivity level for match consummation. The planner is subject to the frictions imposed by the matching technology, which determine the evolution of unemployment. The objective is to choose $\theta$ and $z$ to maximise:

$$
\int_{0}^{\infty} \exp (-\rho t)(Y-u \theta c) d t
$$

where $Y$ is the total instantaneous output of current matches. Unemployment and output evolve according to:

$$
\dot{u}=\delta(1-u)-\lambda \pi(z) u
$$

\footnotetext{
${ }^{13}$ To see this from the dynamic equations (14) to (17), note that when $\phi$ is constant, (16) and (17) determine $\lambda$ as a function of $z$ only. Then from (15) $\dot{z}=0$ is horizontal, and hence so is the saddle path corresponding to any steady state.
} 


$$
\dot{Y}=\lambda \pi(z) u[z+h(z)]-\delta Y
$$

\subsection{Necessary and Sufficient Conditions for Optimality}

Proposition 7 The following conditions are jointly necessary and sufficient for $z$ and $\theta$ to be locally optimal on a dynamic path:

$$
\begin{aligned}
z & =\lambda \eta_{u} S(z)+\frac{\dot{z}}{\rho+\delta} \\
\theta c & =\lambda \eta_{v} S(z) \\
\frac{m \Phi^{\prime \prime}}{\Phi^{\prime}} & <\frac{1-\alpha}{\alpha \sigma}
\end{aligned}
$$

Corollary 1 (Generalised Hosios Condition) A decentralised equilibrium path is a local welfare optimum if and only if $\beta_{1}=\eta_{u}, \beta_{2}=\eta_{v}$, and $\frac{m \Phi^{\prime \prime}}{\Phi^{\prime}}<\frac{1-\alpha}{\alpha \sigma}$.

Proof: By the Principal of Optimality, the social planner's value function $\Omega(Y, u)$ satisfies the Bellman equation:

$$
\rho \Omega(Y, u)=\max _{\theta, z}\left\{Y-u \theta c+\Omega_{Y} \dot{Y}+\Omega_{u} \dot{u}\right\}
$$

We can write down first-order conditions with respect to $z$ and $\theta$, together with envelope conditions for $Y$ and $u:^{14}$

$$
\begin{aligned}
0 & =\Omega_{Y} z-\Omega_{u} \\
\theta c & =\eta_{v} \lambda \pi(z)\left[\Omega_{Y}[z+h(z)]-\Omega_{u}\right] \\
\rho \Omega_{Y} & =1-\delta \Omega_{Y}+\dot{\Omega}_{Y} \\
\rho \Omega_{u} & =\left\{-\theta c+\eta \lambda \Pi(z) h(z)_{Y}\right\}-\delta \Omega_{u}+\dot{\Omega}_{u}
\end{aligned}
$$

Since $\Omega_{Y}$ is bounded, ${ }^{15}$ we can solve (28) and (30) to obtain:

$$
\Omega_{Y}=\frac{1}{\rho+\delta} \quad \text { and } \quad \Omega_{u}=\frac{z}{\rho+\delta}
$$

These are the social marginal values of a unit of output and an unemployed worker respectively; eliminating $\Omega_{Y}$ and $\Omega_{u}$ from (29) and (31) gives the first-order necessary conditions (25) and (26). The second derivatives of the objective function with respect to $\theta$ and $z$ have the same signs as $\frac{\partial^{2} \Phi(m)}{\partial \theta^{2}}$ and $\pi^{\prime}(z)$ respectively. Since the second of these

\footnotetext{
${ }^{14}$ Observe that $\frac{\partial}{\partial Y} \Omega_{Y} \dot{Y}+\frac{\partial}{\partial Y} \Omega_{u} \dot{u}=\Omega_{Y Y} \dot{Y}+\Omega_{Y u} \dot{u}=\dot{\Omega}_{Y}$.

${ }^{15}$ The additional value, $d \Omega$, of an increase in output, $d Y$, lies between 0 and $d Y / \rho$, i.e. what the planner gets if the match that produced the extra output is destroyed immediately, and what she gets if it is never destroyed; so $0 \leq \Omega_{Y} \leq 1 / \rho$.
} 
is always negative, and the cross-partial derivative is zero at a solution of the first-order conditions, the second-order condition is:

$$
\frac{\partial^{2} \Phi(m(u, \theta u))}{\partial \theta^{2}} \equiv \frac{\eta_{v} \Phi}{\theta^{2}}\left(\frac{\alpha m \Phi^{\prime \prime}}{\Phi^{\prime}}-\frac{1-\alpha}{\sigma}\right)<0
$$

A comparison with equations (7) and (8) for the decentralised case establishes the corollary.

Condition (27) states that at an optimum the matching rate must be concave in vacancy creation. If the elasticity of substitution between unemployment and vacancies, $\sigma$, were very high, the planner would choose the number of vacancies so that the market always operated at a point where the matching function was concave in activity. With less substitutability, the planner might choose a convex region of the matching function.

It can be shown in the same way as for the decentralised case that a steady-state solution to the social planner's first-order conditions exists if $\alpha \eta(0)<1$. The only substantive difference is that in the analogue of Lemma $1 z$ depends on market size through the marginal matching rate $\Phi^{\prime}(m)$, rather than the average $\phi(m)$ (see equation (A.1)).

Steady-state welfare is given by:

$$
\rho \Omega=z+\Phi(m) S(z))\left(\frac{\rho}{\delta}+1-\eta\right)
$$

(derived as in section 4.3). So an optimum in a region of decreasing returns will always have a positive social surplus. A positive surplus can arise at an optimum with increasing returns, but if $\eta>1+\rho / \delta$ this requires the total rents to outweigh losses from employment.

\subsection{The Generalised Hosios Condition}

Corollary 1 means that efficiency can in principle be achieved by a policy maker who sets the surplus shares of workers and firms, as in the standard constant returns case. The difference is that with non-constant returns a tax or subsidy is required: the optimal surplus shares do not sum to one. If the optimum has decreasing returns to scale, the surplus must be taxed in order to give agents appropriate search incentives. If the optimum has increasing returns the policy maker must use a subsidy. Note that (as in section 4.3) the subsidy can be financed within the model: at a social optimum with increasing returns and a positive net social surplus (33), it will always be possible to finance the required subsidy from the rents earned by workers - using a lump-sum tax.

The generalisation of the Hosios condition is quite intuitive. With constant returns to scale in matching, search externalities arise when the relative number of agents - market 
tightness - is suboptimal, and efficiency can be achieved by manipulating the relative return to search. With non-constant returns there are also market size effects: additional search externalities that arise when the absolute number of agents is not optimal. To achieve efficiency in this case, it is necessary to control both the relative and absolute return to search. ${ }^{16}$

\section{Conclusions}

The widespread theoretical assumption of constant returns to scale in labour market matching is convenient, but is not well supported by empirical evidence and limits the the adjustment dynamics of matching models. Contrary to widespread assumption the extension of the standard model to non-constant returns is tractable, with simple and intuitive steady-state and dynamic properties. The implication of non-constant returns is that market size matters - the average matching rate increases or decreases with market size depending on returns to scale. Matching markets can have stable decentralised equilibria with either decreasing or increasing returns. When there are multiple equilibria, larger markets deliver higher welfare, although pessimistic expectations can lead to a low-activity equilibrium. The Hosios condition extends easily to the more general model.

Allowing for market size effects means that the adjustment dynamics can be taken seriously in the search for explanations of the evolution of labour market variables. For consistency with empirical evidence on the joint dynamics of unemployment and market tightness, a constant returns model has to rely on high frequency exogenous shocks to the steady state. But with decreasing returns, shocks have longer-lasting effects, and market tightness, the job-finding rate, and reservation wages exhibit plausible endogenous variation as unemployment adjusts on the path to the steady state. Simulations suggest that the quantitative effects are sufficient to improve the performance of the model, but not to account fully for the observed procyclicality of market tightness.

\footnotetext{
${ }^{16}$ With the extension to heterogeneous workers (see section 3.5), the generalised Hosios condition is sufficient for efficiency at the steady state, but not elsewhere on the equilibrium path. Heterogeneous workers create additional search externailities; as shown by Shimer and Smith (2001) with heterogeneity and constant returns, agent-specific taxes and subsidies are required to internalise them.
} 


\section{Appendix}

Proof of Lemma 1: $\theta=\theta_{1}(z) \equiv\left(\frac{\beta_{2}}{\beta_{1} c}\right) z$ follows immediately from (10) and (11). Substituting for $\theta$, equation (11) can be written in terms of $z$ and $m$ only:

$$
\phi(m)=\frac{c}{\beta_{2} S(z)} \frac{\theta_{1}(z)}{\mu\left(\theta_{1}(z)\right)}
$$

The right-hand side is a continuous, differentiable and increasing function of $z$, with limits zero at $z=0$ and $\infty$ at $\bar{y}$. Hence (A.1) has a solution $z=\zeta_{1}(m) \in[0, \bar{y}) \forall m$ as required. Differentiating (A.1):

$$
\frac{m}{z} \frac{d \zeta_{1}}{d m}\left(\frac{z}{h}+1-\alpha\right)=\eta(m)-1
$$

Now consider the flow condition (12). Substituting $u=m / \mu$ and $\theta=\theta_{1}(z)$ :

$$
(\delta-\Phi(m) \pi(z)) \mu\left(\theta_{1}(z)\right)=\delta m
$$

This determines $z=\zeta_{2}(m)$, with $\zeta_{2}(0)=0$, and derivative:

$$
\frac{m}{z} \frac{d \zeta_{2}}{d m}\left(u \alpha-(1-u) \frac{z \pi^{\prime}}{\pi}\right)=u+(1-u) \eta
$$

$\zeta_{2}(m)$ is strictly increasing, reaching a maximum value $\bar{y}$ at $\bar{m}=\mu\left(\theta_{1}(\bar{y})\right)$.

Proof of Proposition 1: An equilibrium is given by $z=\zeta_{1}(m), \theta=\theta_{1}(z)$ and $u=m / \mu(\theta)$ where $m$ satisfies $\zeta_{2}(m)=\zeta_{1}(m)$. Both $\zeta_{2}$ and $\zeta_{1}$ are continuous on $[0, \bar{m}]$, $\zeta_{1}(\bar{m})<\zeta_{2}(\bar{m})=\bar{y}$, and $\zeta_{2}(0)=0$, so a sufficient condition for a solution with $m>0$ is $\zeta_{1}(0)>0$. From (A.1) we see that:

- If $\eta(0)<1, \phi(m) \rightarrow \infty$ as $m \rightarrow 0$, so $\zeta_{1}(0)=\bar{y}$.

- If $\eta(0)=1, \phi(0)$ is finite and strictly positive, so $\zeta_{1}(0) \in(0, \bar{y})$

- If $\eta(0)>1, \phi(0)=0=\zeta_{1}(0)$.

Thus $\eta(0) \leq 1$ guarantees the existence of at least one $m \in(0, \bar{m})$ for which $\zeta_{2}=\zeta_{1}$.

Now consider the case of increasing returns at zero, when there is a zero activity equilibrium: $\zeta_{1}(0)=\zeta_{2}(0)$. Then $\zeta_{1}(m)=\zeta_{2}(m)$ also has a solution at $m>0$ if $\zeta_{1}(m)>\zeta_{2}(m)$ for $m$ close to zero. From (A.4) and (A.2):

$$
\lim _{m \rightarrow 0}\left(\frac{\frac{m}{\zeta_{1}} \frac{d \zeta_{1}}{d m}}{\frac{m}{\zeta_{2}}} \frac{d \zeta_{2}}{d m}\right)=\frac{\alpha \eta(0)-\alpha}{1-\alpha}<1 \quad \text { if } \quad \alpha \eta(0)<1
$$




$$
\Rightarrow \lim _{m \rightarrow 0}\left(\frac{\zeta_{2}}{\zeta_{1}} \frac{d \zeta_{1}}{d \zeta_{2}}\right)<1 \Rightarrow \lim _{m \rightarrow 0}\left(\frac{d \zeta_{1}}{d \zeta_{2}}\right)=\infty
$$

Hence $\alpha \eta(0)<1$ is sufficient for existence of an equilibrium with positive activity, encompassing the decreasing, constant and increasing returns cases.

For uniqueness, at any equilibrium values $(z, m)$ with $m>0$, from (A.4) and (A.2):

$$
\begin{aligned}
\frac{d \zeta_{2}}{d m}-\frac{d \zeta_{1}}{d m} \stackrel{\text { sgn }}{=} u\left(\frac{z}{h}+1-\eta \alpha\right)+(1-u)\left(\eta\left(\frac{z}{h}+1-\alpha\right)-(1-\eta) \frac{z \pi^{\prime}}{\pi}\right) \\
=\left(\frac{z}{h}+1-\eta \alpha\right)-(1-u)(1-\eta)\left(1-\frac{z h^{\prime}}{h}\right)
\end{aligned}
$$

Since $\pi^{\prime}<0$, and $z h^{\prime} / h<1$ by assumption, this is positive if $\eta \leq 1$ from (A.5), and if $1<\eta \leq 1 / \alpha$ from (A.6). So if $\eta(m) \alpha \leq 1$ for all $m, \zeta_{1}$ and $\zeta_{2}$ can only cross once, and the equilibrium is unique.

Proof of Proposition 3: Most of the argument is given in the text; it remains to prove that $\Phi(m) S(z)$ is increasing in $m$ between equilibria. From the proof of Proposition 1 , equilibrium values of $z$ and $m$ satisfy $z=\zeta_{1}(m)$ and:

$$
\frac{d}{d m}(\Phi(m) S(z)) \stackrel{\operatorname{sgn}}{=} \frac{m \Phi^{\prime}}{\Phi}+m \frac{(\pi h)^{\prime}}{\pi h} \frac{d \zeta_{1}}{d m}=\eta(m)-\frac{m}{h} \frac{d \zeta_{1}}{d m}
$$

which is strictly positive from (A.2).

Proof of Lemma 2: Eliminating $m$ and $\theta$ from (16) and (17) we have:

$$
\lambda u=\Phi\left(u \mu\left(\frac{\beta_{2} \lambda S(z)}{c}\right)\right)
$$

Differentiating:

$$
\frac{u}{\lambda}(1-\eta \alpha) d \lambda=(\eta-1) d u-\eta \alpha \frac{u}{h} d z
$$

Hence by the implicit function theorem $\Lambda(u, z)$ is determined provided that $u(1-\eta \alpha)) \neq 0$; this equation also delivers the elasticities.

Proof of Proposition 4: If $\eta\left(m^{*}\right) \alpha<1$, we can prove local stability by showing that $\Delta<0$. This is confirmed immediately when $\eta<1$ by $\Delta \equiv \vec{F}_{1 u} \stackrel{+}{F_{2 z}}-\stackrel{+}{F_{1 z}}+\stackrel{+}{F_{2 u}}<0$. Substituting the expressions for the partial derivatives given in the text, and rearranging, we obtain:

$$
\Delta=-\frac{\delta(\rho+\delta)}{u(1-\eta \alpha)}\left(\frac{z}{h}+1-\eta \alpha-(1-u)(1-\eta)\left(1-\frac{z h^{\prime}}{h}\right)\right)
$$


which is negative when $\eta>1 .{ }^{17}$

In general the saddle path of a linear system: $\left(\begin{array}{c}\dot{x} \\ \dot{y}\end{array}\right)=\left(\begin{array}{cc}a & b \\ c & d\end{array}\right)\left(\begin{array}{l}x \\ y\end{array}\right)$ with $d>0$ is downward-sloping if $c>0$, flat if $c=0$, and upward-sloping if $c<0$. Thus the slope of the saddle path in the neighbourhood of the steady state is determined by the sign of $F_{2 u}$; the slope is equal in sign to $\eta-1$.

If $\eta(m) \alpha<1$ for all $m, \dot{u}=F_{1}(u, z)=0$ and $\dot{z}=F_{2}(u, z)=0$ each determine $z$ as a continuous function of $u$ on $(0,1] . u$ is increasing above $\dot{u}=0$ and decreasing below; $z$ is increasing above $\dot{z}=0$ and decreasing below. Then the saddle path is also continuous on $(0,1]$ : to see this, first note that since the equilibrium is unique and locally stable, $\dot{z}=0$ is below $\dot{u}=0$ for all $u>u^{*}$. The saddle path satisfies the differential equation (20); this is also below $\dot{u}=0$ in the neighbourhood of the equilibrium. But then as we move along the saddle path to the right, away from the equilibrium, it can never cross $\dot{u}=0$; it is either below $\dot{z}=0$, or between the two with $d z / d u<0$. Hence $F_{1}(u, z) \neq 0$ for $u>u^{*}$; a symmetric argument applies for $u<u^{*}$.

Proof of Proposition 5: $\quad \nu$ is the negative root of (21). Evaluating $X$ and $\Delta$ using the expressions in (19) and eliminating $u$ using $\delta(1-u)=\lambda \pi u$ :

$$
\begin{aligned}
X & =(\rho+\delta)-(\delta+\lambda \pi)+\frac{(\rho+\delta) \frac{z}{h}+(1-\eta) \lambda \pi}{1-\eta \alpha} \\
\Delta & =-\frac{\rho+\delta}{1-\eta \alpha}\left((\delta+\lambda \pi)\left(\frac{z}{h}+1-\eta \alpha\right)-(1-\eta) \lambda \pi\left(1-\frac{z h^{\prime}}{h}\right)\right)
\end{aligned}
$$

When $\eta=1$ it can be verified directly that $\nu=\frac{1}{2}\left(X-\sqrt{X^{2}-4 \Delta}\right)=-(\delta+\lambda \pi)$.

Differentiating (21):

$$
\frac{\partial \nu}{\partial \eta}(X-2 \nu)=\frac{\partial \Delta}{\partial \eta}-\nu \frac{\partial X}{\partial \eta}
$$

Then, differentiating the expressions above for $X$ and $\Delta$, and noting that $X-2 \nu=$ $\sqrt{X^{2}-4 \Delta}>0$ we have:

$$
\begin{array}{ccc}
\frac{\partial \nu}{\partial \eta} \stackrel{\text { sgn }}{=} & -(\rho+\delta)\left[(\delta+\lambda \pi) \alpha \frac{z}{h}+\left(1-\frac{z h^{\prime}}{h}\right)(1-\alpha) \lambda \pi\right]-\nu\left[(\rho+\delta) \alpha \frac{z}{h}-(1-\alpha) \lambda \pi\right] \\
\stackrel{\operatorname{sgn}}{=} & -(\rho+\delta) \alpha \frac{z}{h}(\delta+\lambda \pi+\nu)-(1-\alpha) \lambda \pi\left((\rho+\delta)\left(1-\frac{z h^{\prime}}{h}\right)-\nu\right)
\end{array}
$$

Now note that $\frac{\partial \nu}{\partial \eta}$ has the same sign as a linear function of $\nu$, in which the coefficients do not depend on $\eta$. Irrespective of the signs of the coefficients, this implies that $\frac{\partial \nu}{\partial \eta}$ can never change sign. When $\eta=1, \nu=-(\delta+\lambda \pi)$, and from the second expression $\frac{\partial \nu}{\partial \eta}<0$.

\footnotetext{
${ }^{17}$ This expression has the same sign as $\zeta_{1}^{\prime}-\zeta_{2}^{\prime}$, which is not surprising, since $F_{2}=0$ and $F_{1}=0$ are locally identical to $z=\zeta_{1}$ and $z=\zeta_{2}$.
} 
Hence $\frac{\partial \nu}{\partial \eta}<0$ for all $\eta$, and $\nu \gtrless-(\delta+\lambda \pi)$ when $\eta \lessgtr 1$.

Proof of Proposition 6: The slope of the saddle path comes from the eigen vector of $(19): d z / d u=\left(\nu-F_{1 u}\right) / F_{1 z}$.

(i) Adjustment of $\lambda$ :

$$
\begin{aligned}
\frac{d \lambda}{d u} & =\Lambda_{u}+\Lambda_{z} \frac{d z}{d u} \\
\Rightarrow \quad \frac{F_{1 z}}{\lambda} \frac{d \lambda}{d u} & =-\frac{F_{1 z}}{u} \frac{1-\eta}{1-\eta \alpha}-\frac{\eta \alpha}{1-\eta \alpha} \frac{\nu-F_{1 u}}{h} \quad \text { from (18) } \\
\Rightarrow \quad(1-\eta \alpha) \frac{F_{1 z}}{\lambda} \frac{d \lambda}{d u} & =-\lambda \pi(1-\eta)\left(\frac{1}{1-\eta \alpha} \frac{1}{h}+\frac{h^{\prime}}{h}\right)-\frac{\eta \alpha}{h}\left(\nu+\delta+\lambda \pi \frac{\eta(1-\alpha)}{1-\eta \alpha}\right) \\
& =(1-\eta) \lambda \pi^{\prime}-\frac{\eta \alpha}{h}(\nu+\lambda \pi+\delta) \\
& \stackrel{\operatorname{sgn}}{=}-(1-\eta) \quad \text { since } \nu=-(\delta+\lambda \pi) \text { when } \eta=1
\end{aligned}
$$

(ii) Adjustment of $\theta$ :

From $\theta c=\lambda \beta_{2} S(z)$, with similar rearrangement, we obtain:

$$
\begin{aligned}
\frac{1}{\theta} \frac{d \theta}{d u} & =\frac{1}{\lambda} \frac{d \lambda}{d u}-\frac{1}{h} \frac{d z}{d u} \\
(1-\eta \alpha) \frac{F_{1 z}}{\theta} \frac{d \theta}{d u} & =-\frac{1}{h}\left(\nu+\delta+\lambda \pi+(1-\eta) h^{\prime} \lambda \pi\right)
\end{aligned}
$$

Consider $x=\nu+k$ where $k=\delta+\lambda \pi+(1-\eta) h^{\prime} \lambda \pi$. From (21) $x$ is the lower of the solutions of the quadratic:

$$
x^{2}-x X+\Delta_{1}=0 \quad \text { where } \quad \Delta_{1}=\Delta+X k+k^{2}
$$

Using the expressions for $\Delta$ and $X$ from the proof of Proposition 5, and rearranging:

$$
\Delta_{1}=\lambda \pi(1-\eta)\left(h^{\prime}+\frac{1}{1-\eta \alpha}\right)(\rho+\delta+k)
$$

If $x=0$ for any value of $\eta, \Delta_{1}$ must be zero. This is true when $\eta=1$, in which case (Proposition 5) $\nu=-(\delta+\lambda \pi)$. Suppose $x=0$ for any other $\eta$. Then $k$ is positive, and since $h^{\prime}>-1$ the expression above for $\Delta_{1}$ is non-zero, which is a contradiction. Finally note that, differentiating the quadratic:

$$
\eta=1 \Rightarrow \frac{d x}{d \eta} \stackrel{\operatorname{sgn}}{=} \frac{\partial \Delta}{\partial \eta}=-\left(h^{\prime}+\frac{1}{1-\alpha}\right)(\rho+\delta+\delta+\lambda \pi)<0
$$


Hence:

$$
x \stackrel{\text { sgn }}{=}(1-\eta) \quad \text { and } \quad \frac{1}{\theta} \frac{d \theta}{d u} \stackrel{\text { sgn }}{=}-(1-\eta)
$$

(iii) Adjustment of $v$ :

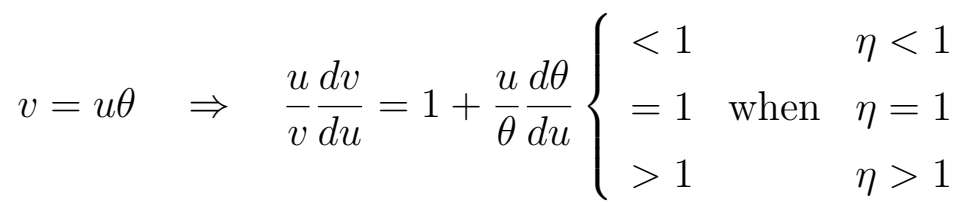

From (A.8):

$$
\frac{1}{v} \frac{d v}{d u}=-\frac{1}{h}\left(\nu+\delta-\eta(1-\alpha) h^{\prime} \lambda \pi\right)
$$

By the same method as that used in (ii) for $x$, we can show that $y=\nu+\delta-\eta(1-\alpha) h^{\prime} \lambda \pi$ is negative for all $\eta$, so $d v / d u$ is positive for all $\eta$.

\section{References}

Acemoglu, D. (1997). 'Technology, unemployment and efficiency', European Economic Review, 19, 1-20.

Acemoglu, D. (2001). 'Good jobs versus bad jobs', Journal of Labor Economics, 41(3-5), $525-33$.

Alvarez, F. and Shimer, R. (2011). 'Search and rest unemployment', Econometrica, 79(1), $75-122$.

Andolfatto, D. (1996). 'Business cycles and labor market search', American Economic Review, 86, 112-32.

Baker, S., Hogan, S. and Ragan, C. (1996). 'Is there compelling evidence against increasing returns to matching in the labour market?', Canadian Journal of Economics, 29, 976-93.

Berman, E. (1997). 'Help wanted, job needed: estimates of a matching function from employment service data', Journal of Labor Economics, 15(1), S251-92.

Blanchard, O.J. and Diamond, P.A. (1990). 'The aggregate matching function', in Growth, Productivity and Unemployment (P. A. Diamond, ed.). Cambridge: MIT Press.

Boldrin, M., Kiyotaki, N. and Wright, R. (1993). 'A dynamic equilibrium model of search, production and exchange', Journal of Economic Dynamics and Control, 17, 723-758.

Burda, M. and Wyplosz, C. (1994). 'Gross worker and job flows in Europe', European Economic Review, 38(6), 1287-315.

Burdett, K. and Wright, R. (1998). 'Two-sided search with non-transferable utility', Review of Economic Dynamics, 1, 220-245.

Burgess, S. and Profit, S. (2001). 'Externalities in the matching of workers and firms in 
Britain', Labour Economics, 8, 313-33.

Camera, G. (2000). 'Money, search, and costly matchmaking', Macroeconomic Dynamics, 4(3), 289-323.

Cole, H.L. and Rogerson, R. (1999). 'Can the Mortensen-Pissarides matching model match the business-cycle facts?', International Economic Review, 40, 933-59.

Coles, M. and Smith, E. (1996). 'Cross-section estimation of the matching function: evidence from England and Wales', Economica, 63, 589-597.

Cooper, R. (1999). Coordination Games: Complementarities and Macroeconomics (Cambridge University Press).

Cooper, R. and John, A. (1988). 'Coordinating coordination failures in Keynesian models', Quarterly Journal of Economics, 103(3), 441-63.

den Haan, W.J., Ramey, G. and Watson, J. (2000). 'Job destruction and propagation of Shocks', American Economic Review, 90(3), 482-98.

Diamond, P.A. (1982). 'Aggregate demand management in search equilibrium', Journal of Political Economy, 90, 881-94.

Diamond, P. and Fudenberg, D. (1989). 'Rational expectations business cycles in search equilibrium', Journal of Political Economy, 97(3), 606-20.

Drazen, A. (1988). 'Self-fulfilling optimism in a trade-friction model of the business cycle', American Economic Review, 78(2), 369-72.

Fahr, R. and Sunde, U. (2004). 'Occupational job creation: patterns and implications', Oxford Economic Papers, 56, 407-35.

Garibaldi, P. and Wasmer, E. (2005). 'Equilibrium search unemployment, endogenous participation and labor market flows', Journal of the European Economic Association, 3(4), 851-82.

Hagedorn, M. and Manovskii, I. (2008). 'The cyclical behavior of equilibrium unemployment and vacancies revisited', American Economic Review, 98(4), 1692-706.

Hall, R.E. (2005). 'Employment efficiency and sticky wages: evidence from flows in the labor market', Review of Economics and Statistics, 87(3), 397-407.

Hall, R.E. and Milgrom, P.R. (2008). 'The limited influence of unemployment on the wage bargain', American Economic Review, 98(4), 1653-74.

Hosios, A.J. (1990). 'On the efficiency of matching and related models of search and unemployment', Review of Economic Studies, 57, 279-98.

Howitt, P. and McAfee, R.P. (1987). 'Costly search and recruiting', International Economic Review, 28(1), 89-107.

Kangasharju, A., Pehkonen, J. and Pekkala, S. (2005). 'Returns to scale in a matching model: evidence from disaggregated panel data', Applied Economics, 37, 115-18.

Kano, S. and Ohta, M. (2005). 'Estimating a matching function and regional matching efficiencies: Japanese Panel Data for 1973-1999', Japan and the World Economy, 17, 
$25-41$.

Keller, G., Roberts, K. and Stevens, M. (2007). 'Unemployment, participation and market size' (Oxford University Department of Economics Discussion Paper 362).

Layard, R., Nickell, S. and Jackman, R. (1991). Unemployment (Oxford: Oxford University Press).

Merz, M. (1995). 'Search in the labor market and the real business cycle', Journal of Monetary Economics, 36, 269-300.

Merz, M. (1999). 'Heterogeneous job-matches and the cyclical behavior of labor turnover', Journal of Monetary Economics, 43, 91-124.

Mortensen, D.T. (1989). 'The persistence and indeterminacy of unemployment in search equilibrium', Scandinavian Journal of Economics, 91(2), 347-70.

Mortensen, D.T. (1999). 'Equilibrium unemployment dynamics', International Economic Review, 40(4), 889-914.

Mortensen, D.T. and Pissarides, C.A. (1994). 'Job creation and job destruction in the theory of unemployment', Review of Economic Studies, 61, 397-415.

Mortensen, D.T. and Pissarides, C.A. (1999). 'Job reallocation, employment fluctuations, and unemployment differences', in Handbook of Macroeconomics (M. Woodford and J. Taylor, eds.). Amsterdam: North Holland, 1171-228.

Munich D., Svejnar, J. and Terrell, K. (1999). 'Worker-firm matching and unemployment in transition to a market economy: (why) were the Czechs more successful than others?' (WP No. 107, Davidson Institute, Michigan Business School).

Petrongolo, B. and Pissarides, C.A. (2001). 'Looking into the black box: a survey of the matching function', Journal of Economic Literature, 39, 390-431.

Pissarides, C.A. (1984). 'Search intensity, job edvertising, and efficiency', Journal of Labor Economics, 2, 128-143.

Pissarides, C.A. (1986). 'Unemployment and vacancies in Britain', Economic Policy, 1(3), 499-559.

Pissarides, C.A. (2000). Equilibrium Unemployment Theory, 2nd Edition (Cambridge: MIT Press).

Rogerson, R., Shimer, R. and Wright, R. (2005). 'Search-theoretic models of the labor market: A Survey', Journal of Economic Literature, XLIII, 959-88.

Rogerson, R. and Shimer, R. (2011). 'Search in macroeconomic models of the labor market', in Handbook of Labor Economics v. 4a (O. Ashenfelter and D. Card, eds.). Amsterdam: North Holland, 619-700.

Schmitt-Grohe, S. and Uribe, M. (2004). 'Solving dynamic general equilibrium models using a second-order approximation to the policy function', Journal of Economic Dynamics and Control, 28, 755-75.

Shimer, R. (2005). 'The cyclical behavior of equilibrium unemployment and vacancies', 
American Economic Review, 95, 25-49.

Shimer, R. and Smith, L. (2001). 'Matching, search and heterogeneity', Advances in Macroeconomics, 1, Article 5.

van den Berg, G.J. (2003). 'Multiple equilibria and minimum wages in labour markets with informational frictions and heterogeneous production technologies', International Economic Review, 44, 1337-57.

van Ours, J. (1991). 'The efficiency of the Dutch labour market in matching unemployment and vacancies', De Economist, 139(3), 358-78.

Veracierto, M. (2004). 'On the cyclical behaviour of employment, unemployment and labor force participation' (WP 2002-12, Federal Reserve Bank of Chicago).

Warren, R.S. (1996). 'Returns to scale in a matching model of the labor market', Economics Letters, 50, 135-42.

Yashiv, E. (2000). 'The determinants of equilibrium unemployment', American Economic Review, 90(5), 1297-392. 